\title{
An Amalab-Movie Creation Approach Model: Utilizing Statistical Science To Design Anime Hits
}

Akinori Ishikawa, Aoyama Gakuin University, Japan Koyama Hiroki, Aoyama Gakuin University, Japan Kakuro Amasaka, Aoyama Gakuin University, Japan

\begin{abstract}
The authors have created an "Amalab-Movie Creation Approach Model, A-MCAM", by utilizing statistical science to support filmmakers' design hit movies. This paper first identifies the factors that make an Anime hit movie by making the expertise and knowledge of Anime movie producers explicit. Second, explicit knowledge is then made of factors that have an emotional impact on moviegoers to identify key subjective elements in films. Third, cause and effect links are then forged between these subjective elements and those in hit movies. Finally, this knowledge and the research process are used to create an A-MCAM. The authors then enlist the support of movie producers in verifying this model, which is deemed a successful model for improving the quality of hit filmmaking.
\end{abstract}

Keywords: Knowledge of Movie Producers; Emotional Impact on Moviegoers; Anime Movie

\section{INTRODUCTION}

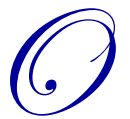

ne of the major challenges facing the Japanese film industry is the creation of film projects that will revitalize the market (Culture and Information Ministry, 2003). While the number of cinema screens and the number of films screened has soared in recent years, the key measure of box office receipts has remained flat at about $¥ 200$ billion (in the 21 st century) with many industry sources pointing to planning and development - the backbone of film production - as the cause. Then the authors created an "Amalab-Movie Creation Approach Model, A-MCAM", by utilizing statistical science to support filmmakers' design hit movies. This is a tool to support the conception of film projects by film producers who play the central role in projects (Amasaka, 2009).

Specifically, this research targets animated films for general audiences, which are aimed at the men and women of all ages. First, it makes the knowledge and expertise of film producers explicit and assesses the hit factors behind animated film projects. Next, it makes the factors that have an impact on moviegoers explicit and assesses these factors. Finally, it assesses the causal relationship between moviegoers' impact factors and hit animated film project factors.

For the purpose of improving the quality of hit animated film projects, the authors collaborated with film producers to verify the validity of the model and were able to achieve the given results.

\section{BACKGROUND}

Japanese domestic box office receipts have been flat at around $¥ 200$ billion (in the 21 st century). Planning and development - the backbone of filmmaking - is at an impasse and the absolute number of hit films infused with new creativity is stagnated and declining (Koyama et al., 2011). As far as the authors are aware, the current situation is that large companies hold superior projects, with medium and small businesses producing the projects not financed by the big companies. Great differences in profitability inevitably rise and many film companies are forced 
into bankruptcy. Regardless of company size, the Japanese film industry today is in need of a new methodology to enable the conception and creation of hit film projects that will revitalize the market (Guber, 2008; Imamura, 2008; Kohara and Yamada, 2010).

\section{STUDY PURPOSE}

The authors have adopted a scientific approach to solve the problems described above and in Figure 1, they propose the Amalab Movie Creation Approach Model, or A-MCAM, to contribute to the conception of film projects by producers. Through the creation of A-MCAM, we aim to support the rational planning of hit film projects by revising the implicit hit film project creation process that producers have conducted so far.

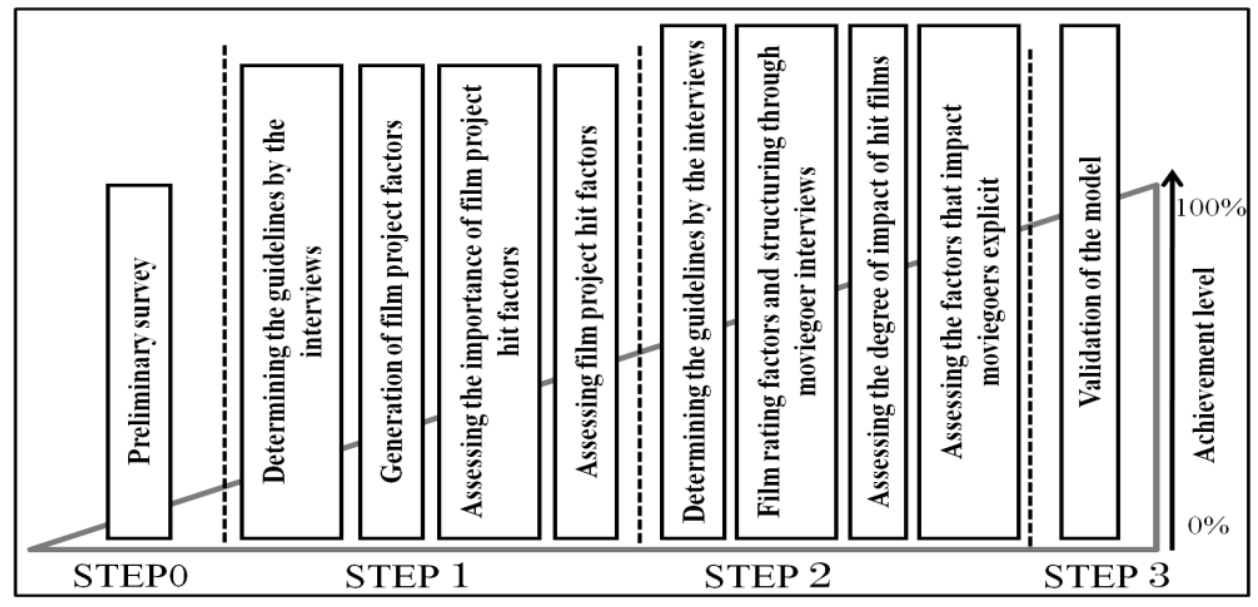

Figure 1: An Amalab-Movie Creation Approach Model

\section{Making Film Producers' Expertise and Knowledge Explicit}

\section{Determination of Research Guidelines through Interviews}

The object of this research is animated films for general audiences; the reasons being 1) greater market growth is expected for this genre than for live-action Japanese film projects and 2) we believe that the large existing number of works already introduced overseas makes this a valuable target of research (Tanimura, 2005).

Next, we will define what producers of animated films for general audiences deem a "hit film". Through interviews with four producers of animated films for general audiences (one producer from a DVD package manufacturer, two from television stations, and one from a distributor), we define "hit animated films for general audiences" (hereafter "hit films") as those animated films for general audiences having box office receipts of $¥ 1$ billion or more and a return on investment of $200 \%$ or more.

\section{Generation of Film Project Factor}

We will extract the factors (items) required by film producers for the generation of film projects. We conducted an interview survey of producers of animated films for general audiences (the above four producers) on the question of the highest priority points in the making of animated film projects. The results, organized and categorized according to the affinity diagram method, are shown in Figure 2 (Investigation society, 2004; Amasaka, 2007; Amasaka and Nagasawa, 2000). The result of grouping according to the affinity diagram method, as shown in the figure, were five groups - "Film content", "Film production", "Film advertising", "Film distribution", and "Budget and contracts". 


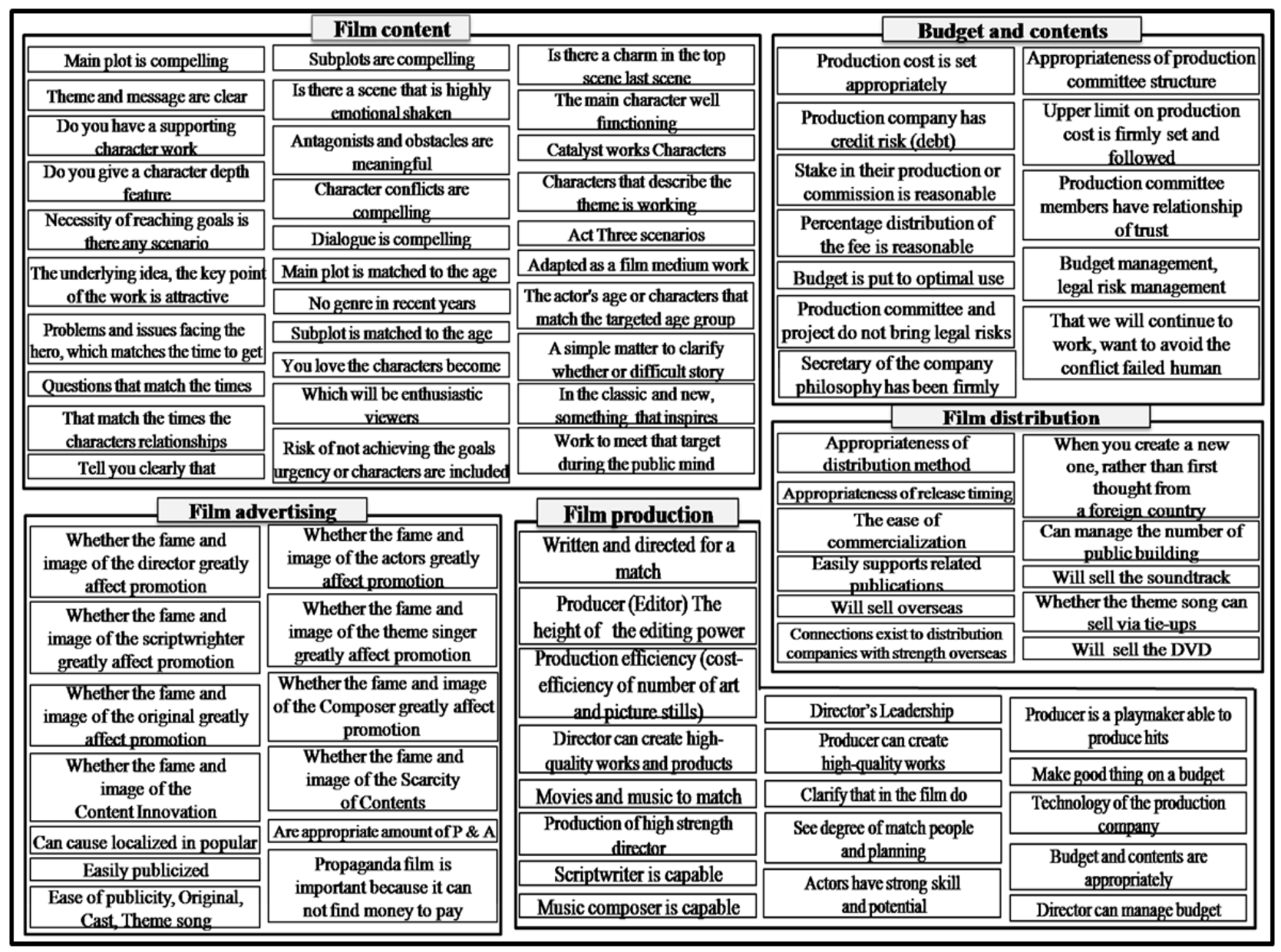

Figure 2: Affinity Diagram of Film Producers' Film Project Structure Factors

From here, we conducted further interviews with each film producer to narrow down, combine, or otherwise modify and thereby refine the factors required for film project structuring. The resulting final producers' film project structure factors, put together through interviews, are shown in Table 1. As shown in the table, we set these as five groups - "Content of film", "Production plan", "Promotion plan", "Distribution plan", and "Business scheme", per Figure 2, and generated 45 factors necessary for film projects that compose the groups.

Next, using the film project factors generated, we asked 15 producers of animated films for general audiences, via questionnaire, which of the items producers place importance on and to what degree. The questions, broadly divided, are: "From the 45 items (1-45 in Table 1) that compose film projects, select the item(s) that you consider most important", "Rate the degree of importance of each of the following groups of items in the creation of hit animated films for general audiences, using a score of 10 for the item(s) you selected as most important in the previous question and relative scores of 1 to 10 for other items; and then "State your company and past achievements as a film producer". Through this questionnaire, we were able to capture the items that film producers feels are the most important when constructing hit film projects.

\section{Assessing Film Project Hit Factors}

Through principle component analysis of the questionnaires as shown in Table 2 and Figure 3, we explored the hit factors behind film projects. Table 2 lists those items with principle component 1 factor loading of 0.8 or higher (with "No." in Table 2 corresponding to the numbers (1-45 in Table 1). 
From this analysis, as items with high principle component 1 factor loading are universally important factors, such as the aptness of characters and casting and the ease of commercialization, we consider principle component 1 as the axis representing "Universality". In the same manner, as items with high factor loading in the principle component 2 axis are film project factors that are highly sensitive to the times in which the film is released, such as whether the fame and image of the director greatly affect promotion or whether the theme song can sell via tie-ups, we consider this to be the axis representing "Temporality".

From these analysis results, the universality of principle component 1 is "the ability to capture the basics" and is a universally important hit factor group that should be incorporated into projects. The temporality of principle component 2 is "the ability to capture the times" and is a hit factor group easily affected by the times, which should be employed according to circumstances.

Table 1: 45 Factors Necessary for Film Project

\begin{tabular}{|l|l|}
\hline \multicolumn{1}{|c|}{ 【1】 Film content } \\
\hline \hline 1 & Theme and message are clear \\
\hline 2 & First and last scenes are compelling \\
\hline 3 & Contains strongly emotional scenes \\
\hline 4 & Main characters are compelling \\
\hline 5 & Antagonists and obstacles are meaningful \\
\hline 6 & Character conflicts are compelling \\
\hline 7 & Has three-act structure (structure that maintains interest) \\
\hline 8 & Dialogueis compelling \\
\hline 9 & Points that are key to the underlying idea are compelling \\
\hline 10 & Main plot is compelling \\
\hline 11 & Subplots are compelling \\
\hline 12 & $\begin{array}{l}\text { Conclusion of the movie matches the market at the time of } \\
\text { release }\end{array}$ \\
\hline 13 & Has potential for niche or local popularity \\
\hline & \multicolumn{1}{|c|}{ [2】 Production plan } \\
\hline \hline 14 & The aptness of characters and casting \\
\hline 15 & Actors have strong skill and potential \\
\hline 16 & Scriptwriter is capable \\
\hline 17 & Music composer is capable \\
\hline 18 & $\begin{array}{l}\text { Production efficiency (cost-efficiency of number of art and } \\
\text { picture stills) }\end{array}$ \\
\hline 19 & Producer can manage budget \\
\hline 20 & Producer can create high-quality works \\
\hline 21 & Producer is a playmaker able to produce hits \\
\hline 22 & Director can create high-quality works and products \\
\hline
\end{tabular}

\begin{tabular}{|l|l|}
\hline \multicolumn{1}{|c|}{ 【3】 Promotionplan } \\
\hline 23 & Whether the fame and image of the director greatly affect promotion \\
\hline 24 & Whether the fame and image of the actors greatly affect promotion \\
\hline 25 & $\begin{array}{l}\text { Whether the fame and image of the scriptwrighter greatly affect } \\
\text { promotion }\end{array}$ \\
\hline 26 & $\begin{array}{l}\text { Whether the fame and image of the theme singer greatly affect } \\
\text { promotion }\end{array}$ \\
\hline 27 & Whether the fame and image of the original greatly affect promotion \\
\hline 28 & Are appropriate amount of P \& $\mathrm{G}$ \\
\hline 29 & Easily allows product or advertising tie-ups \\
\hline 30 & Easily publicized \\
\hline 31 & Age group of characters suits age group of target audience \\
\hline & \multicolumn{1}{|c|}{ 【】 Distribution plan } \\
\hline \hline 32 & Appropriateness of distribution method \\
\hline 33 & Appropriateness of release timing \\
\hline 34 & Whether the theme song can sell via tie-ups \\
\hline 35 & The ease of commercialization \\
\hline 36 & Easily supports related publications \\
\hline 37 & Will sell overseas \\
\hline 38 & Connections exist to distribution companies with strength overseas \\
\hline \\
\hline 39 & Appropriateness of production committee structure \\
\hline 40 & Production cost is set appropriately \\
\hline 41 & Upper limit on production cost is firmly set and followed \\
\hline 42 & Production company has credit risk (debt) \\
\hline 43 & Budget is put to optimal use \\
\hline 44 & Production committeemembers have relationship of trust \\
\hline 45 & Production committee and project do not bring legal risks \\
\hline
\end{tabular}

Table 2: Results of Principal Component Analysis of Questionnaire for Film Producers (Items with Principal Component 1 Factor Loading of 0.8 or Higher)

\begin{tabular}{|l|l|r|}
\hline No & \multicolumn{1}{|c|}{ Variable name } & $\begin{array}{c}\text { principal } \\
\text { component } \\
1\end{array}$ \\
\hline \hline 10 & Main plot is compelling & 0.871 \\
\hline 11 & Subplots are compelling & 0.863 \\
\hline 14 & the aptness of characters and casting & 0.836 \\
\hline 22 & $\begin{array}{l}\text { Director can create high-quality works and } \\
\text { products }\end{array}$ & 0.912 \\
\hline 27 & $\begin{array}{l}\text { Whether the fame and image of the original } \\
\text { greatly affect promotion }\end{array}$ & 0.861 \\
\hline 32 & Appropriateness of distribution method & 0.902 \\
\hline 35 & The ease of commercialization & 0.882 \\
\hline 39 & $\begin{array}{l}\text { Appropriateness of production committee } \\
\text { structure }\end{array}$ & 0.865 \\
\hline
\end{tabular}


Next, as shown in Figure 3, we used a principal component score scatter plot to group film producers (A to $\mathrm{O}$ represent the film producers). As shown in the figure, we grouped 15 film producers into the following four groups according to past performance: 1) "Blockbuster producers" who have produced many hit films in the past, 2) "Hitproducers" who have not achieved a hit film (per our definition) but have achieved several hits in excess of ¥1.5 billion or with high return on investment, 3) "Steady producers" who have no big hits but have no films with return on investment under $100 \%$ and 4) "Volatile producers" who have achieved high return on investment but who also have films with return on investment under $100 \%$ or with less than $¥ 100$ million in box office receipts. From this, we were able to consider producers with higher past achievements as producers incorporating universally important factors and making use of factors affected by the times as conditions demand.

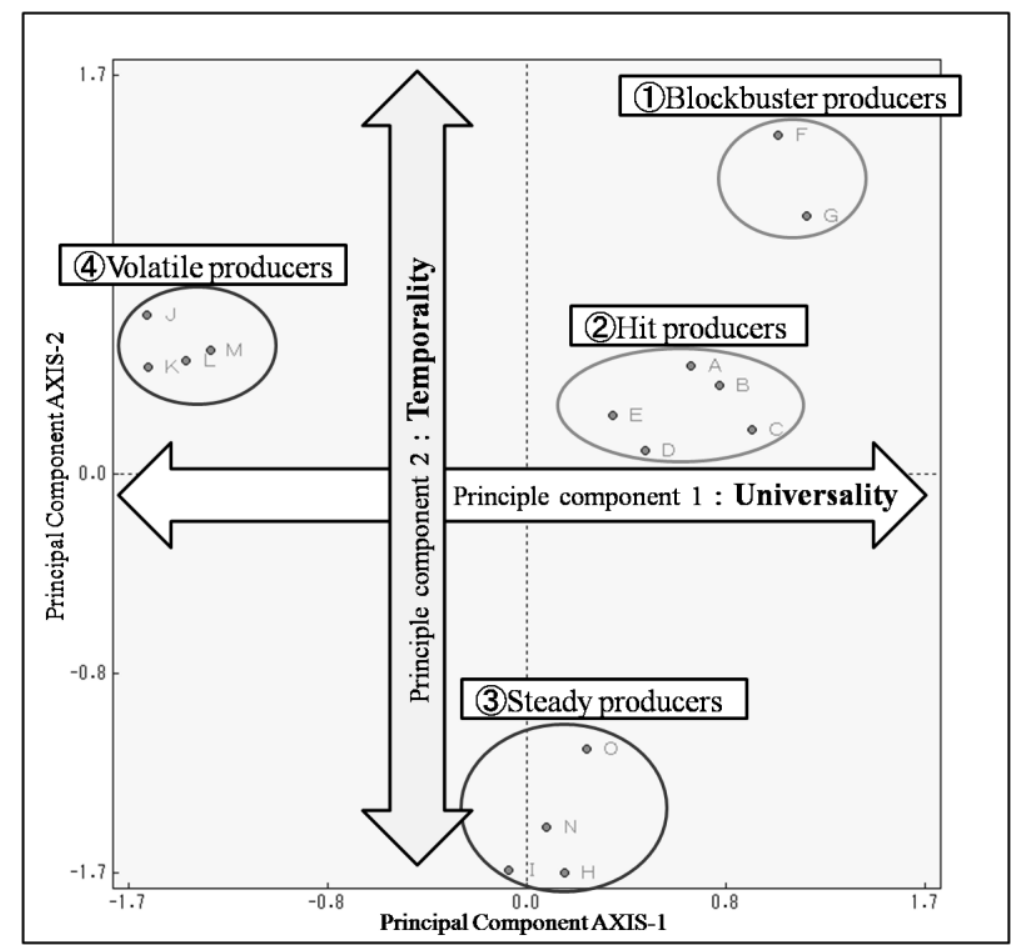

Figure 3: Results of Principal Component Analysis of Questionnaire for Film Producers

In addition, factors with a principle component 1 and 2 loading factor of 0.7 or higher are listed in Table 3 (with "No." in Table 3 corresponding to the numbers 1-45 in Table 1). We set the factor group for principal component 1 (15 items) as "universal hit factors", set the factor group for principal component 2 (10 items) as "temporal hit factors", and identified the hit factors for both universality and temporality. From these, we were able to explicitly draw out the knowledge and experience of film producers in generating hit film projects. 
Table 3: Universal Hit Factors and Temboral Hit Factors

\begin{tabular}{|c|c|}
\hline Universal hit factors ( 15 items) & Temporal hit factors ( 10 items) \\
\hline 1 Theme and message are clear & 2 First and last scenes are compelling \\
\hline 6 Character conflicts are compelling & 5 Antagonists and obstacles are meaningful \\
\hline 7 Has three-act structure (structure that maintains interest) & 13 Has potential for niche or local popularity \\
\hline 8 Dialogue is compelling & 15 Actors have strong skill and potential \\
\hline 10 Main plot is compelling & \multirow{2}{*}{$\begin{array}{l}\text { Whether the fame and image of the director greatly affect } \\
\text { promotion }\end{array}$} \\
\hline 11 Subplots are compelling & \\
\hline 14 The aptness of characters and casting & 25 Whether the fame and image of the scriptwrighter greatly \\
\hline 20 Producer can create high-quality works & anect promonon \\
\hline 22 Director can create high-quality works and products & 29 Easlly allows product or advertising tie-ups \\
\hline Whether the fame and image of the original greatly affect & 30 Easily publicized \\
\hline 27 promotion & 34 Whether the theme song can sell via tie-ups \\
\hline 32 Appropriateness of distribution method & \multirow[t]{5}{*}{36 Easily supports related publications } \\
\hline 33 Appropriateness of release timing & \\
\hline 35 The ease of commercialization & \\
\hline 39 Appropriateness of production committee structure & \\
\hline 44 Production committee members have relationship of trust & \\
\hline
\end{tabular}

\section{Making the Hit Factors that Impact Moviegoers Explicit}

\section{Film Rating Factors and Structuring through Moviegoer Interview}

We identified the factors behind films that are considered as hits by moviegoers of animated films for general audiences. In interviews with 17 moviegoers of animated films for general audiences, the item generating the most opinion was "Films that have an impact on me or on others". We then extracted the specific factors of films that have an impact on moviegoers. The method for extracting the factors sought free responses to the question, "What parts of animated films for general audiences had an impact on you in the past?" from 17 moviegoers.

First, using word frequency analysis of the full text data to quantitatively assess what sort of factors moviegoers of animated films for general audiences focus on, we extracted terms such as "scenes", "characters", "pictures" "backgrounds", "music", and "voice actors". Among these, we inferred that the most commonly given term "scenes" is the one that most easily creates a lasting impression on moviegoers, and in follow-up interviews with the moviegoers regarding elements that compose "scenes", we extracted specific expressions (factors), such as "direction", "worldview", "pictures", "characters", and "acting".

Further, we indicate the elements that compose each of these items and clarified their relevance using a word network, creating the moviegoer film rating structural model shown in Figure 4. In the figure, a concept of verticality exists among the factors, indicated by arrows connecting the upper concepts with the factors that compose them. In this way, we enabled a structural assessment of moviegoers' film rating factors. 


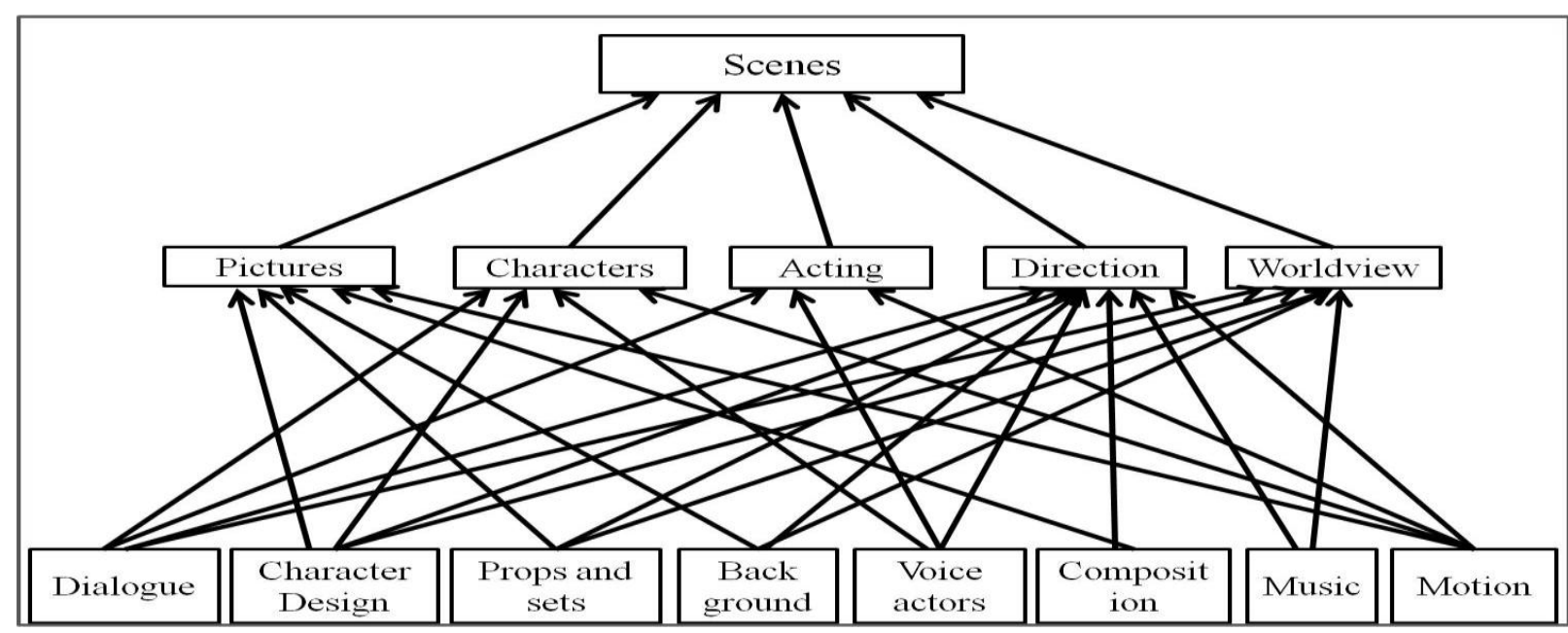

Figure 4: The Moviegoer Film Rating Structural Mode

Assessing the Degree of Impact of Hit Film

In addition, we extracted what moviegoers consider film hit factors. Specifically, we conducted a questionnaire survey using moviegoers' film rating factors to assess the degree of importance of each factor. To extract specific factors related to temporality and universality of films, the questionnaire divided hit animated films for general audiences into films of the 1980s and earlier and films of the 1990s onward. We surveyed the sort of factors in animated films for general audiences that had an impact on moviegoers and attempted to discover what lay behind priority ordering and their relevance.

The questionnaire targeted 32 moviegoers of animated films for general audiences. Based on the results of this survey, we used covariance structure analysis to extract the factors in hit films that moved moviegoers. Table 4 shows the path coefficients for films through the 1980s and films from the 1990s. GFI of Analysis through the 1980s is 0.82 and from the $1990 \mathrm{~s}$, it is 0.724 . We consider that reliability of those analyses is not bad. From these results, we found that universal hit film factors are "direction", "worldview and setting", "dialogue", "music and sound effects", and "voices and voice actors".

In addition, we found that temporal hit film factors for moviegoers of animated films for general audiences through the 1980s were "props and sets", while temporal hit film factors for moviegoers of animated films for general audiences from the 1990s were "characters", "character design", "voices and voice actors", and "dialogue". Through this, we were able to make moviegoers' film rating factors explicit. 
Table 4: Path Coefficients for Hit Animated Films through the 1980s

\begin{tabular}{|c|c|c|c|}
\hline & & Path coef & icients \\
\hline & & \begin{tabular}{l|l}
$1980 s$ & \\
\end{tabular} & 1990s \\
\hline Direction & $<--$ Dialogue & 0.418 & 0.337 \\
\hline Worldview & $<--$ Dialogue & 0.448 & 0.386 \\
\hline Characters & $<--$ Dialogue & -0.155 & 0.341 \\
\hline Acting & $<--$ Dialogue & 0.304 & 0.296 \\
\hline Wor1dview & $<--$ Character Design & -0.128 & 0.532 \\
\hline Pictures & $<--$ Character Design & 0.157 & 0.094 \\
\hline Characters & $<--$ Character Design & 0.331 & 0.646 \\
\hline Direction & $<--$ Character Design & -0.89 & 0.468 \\
\hline Direction & $<--$ Props and sets & 0.342 & -0.16 \\
\hline Worldview & $<--$ Props and sets & 0.566 & 0.38 \\
\hline Pictures & $<--$ Props and sets & 0.67 & 0.066 \\
\hline Direction & $<--$ Backgrounds & 0.100 & -0.239 \\
\hline Worldview & $<--$ Backgrounds & 0.082 & 0.003 \\
\hline Pictures & $<--$ Backgrounds & 0.015 & -0.35 \\
\hline Characters & $<--$ Voice actors & 0.373 & 0.345 \\
\hline Acting & $<--$ Voice actors & 0.373 & 0.303 \\
\hline Direction & $<--$ Voice actors & 0.37 & 0.353 \\
\hline Direction & $<--$ Composition & -0.7 & 0.124 \\
\hline Pictures & $<--$ Composition & 0.135 & 0.93 \\
\hline Direction & $<--$ Music & 0.433 & 0.442 \\
\hline Worldview & $<--$ Music & 0.371 & 0.474 \\
\hline Direction & $<--$ Motion & -0.134 & -0.64 \\
\hline Pictures & $<--$ Motion & -0.168 & -0.127 \\
\hline Characters & $<--$ Motion & 0.122 & -0.57 \\
\hline Acting & $<--$ Motion & 0.082 & 0.103 \\
\hline Scenes & $<--$ Direction & -0.89 & 0.436 \\
\hline Scenes & $<--$ Worldview & 0.241 & 0.314 \\
\hline Scenes & $<--$ Pictures & -0.169 & -0.183 \\
\hline Scenes & $<--$ Characters & 0.4 & 0.286 \\
\hline Scenes & $<--$ Acting & 0.53 & 0.077 \\
\hline
\end{tabular}

\section{Verifying the Validity of A-MCAM}

Upon requesting an evaluation of A-MCAM from the above four film producers, the model was praised for "Clearly itemizing (factorizing) the previously implicit factors that compose film projects". Further, praise was also given for points such as "Quantitatively surveying film project structure though questionnaires, something previously done only subjectively". On the other hand, we also received comments such as "The amount of budget, persons, and time required to carry out a serial research approach should be made clear" and "Steps should be concretely indicated, up through how data is to be acquired from film producers".

Summarizing the results of verification of A-MCAM, the points that were rated highly were its status as a research approach model utilizing quantitative analysis previously not performed in the film industry and its capturing of the knowledge and expertise of film producers. In the future, to make this model of use to the film industry by further increasing its practicality, it is hoped that we will refine it within the concept of actual film projects.

\section{CONCLUSION}

This study consists of an Amalab Movie Creation Approach Model - or A-MCAM - which uses a scientific approach to assist film producers. Through this model, we revealed factors behind hit film projects for both film 
producers and moviegoers. The authors, in collaboration with film producers on the conceived model, carried out verification of its validity and were able to achieve the given results.

\section{AUTHOR INFORMATION}

Akinori Ishikawa is a graduate student of the College of Science and Engineering at Aoyama Gakuin University. E-mail: c5610161@aoyama.jp (Corresponding author)

Hiroki Koyama is a graduate student of the College of Science and Engineering at Aoyama Gakuin University. E-mail: kurumecity530@gmail.com

Kakuro Amasaka is a Professor in the School of Science and Engineering at Aoyama Gakuin University, Japan. He received his Ph.D. degree in Precision Mechanical and System Engineering, Statistics and Quality Control at Hiroshima University in 1997. His current research and teaching interests are in the general area of production engineering. In particular, he is interested in New JIT. He is a chairman of JOMSA (2008-). E-mail: Kakuro_amasaka@ise.aoyama.ac.jp (Corresponding author)

\section{REFERENCES}

1. Related Industries Division of Culture and Information Ministry of Economy Commerce and Information Policy Bureau., (2003), "Film production Strengthening Research on Producing Content Features", pp.1045

2. Amasaka, K., (2009), "Proposal and validity of patent value appraisal model "TJS-PVAM" -development of "Science TQM" in the corporate strategy-", China-USA Business Review, 8, 7, pp.45-56

3. Koyama, H., Yoshida, N. and Amasaka, K. (2011), "The A-MPM decision-making model for film project investments: a partnering with filmmakers”, International Business \& Economics Journal, 11, 7, pp. 323 330.

4. Guber, P., (2008), "The four truths of the storyteller", Diamond Harvard Business Review, pp.80-92

5. Imamura, M., (2008), "Study of the Customers in the Movie Captures the Spirit", Aoyama Gakuin University

6. Kohara, D. and Yamada, M., (2010), "Making Compelling Movie Poster-Using Statistical Science and an Exe Mark Recorder", Aoyama Gakuin University

7. Tanimura, S., (2005), "Study of Consumer Behavior Model Theory for AIDA", Aoyama Gakuin University

8. Investigation society concerning contents evaluation and business model, (2004) "Investigation research report concerning contents evaluation in 2004 fiscal year and business model"

9. Amasaka, K., (2007), "Proposal of marketing SQC to revolutionize dealers' sales activities -a demonstrative study on customer science by utilizing Science SQC-“, Proceedings of the16th International Conference Production Research, Praha, Czech Public, pp.1-9 (CD-ROM)

10. Amasaka, K. and Nagazawa. S., (2000), "Basic and Advanced Sensory Evaluation for Sensitivity in Automotive Engineering", Japanese Standards Association 


\section{NOTES}

